\title{
Diagnosis and Evaluation of Corrosive Oesophageal Injuries
}

\author{
Altintoprak Fatih $^{1 *}$, Arslan Yusuf ${ }^{2}$, Uzunoglu Mustafa Yener2 \\ ${ }^{1}$ Department of General Surger, Sakarya University Faculty of Medicine, Sakarya, Turkey \\ ${ }^{2}$ Department of General Surgery, Sakarya University Research and Educational Hospital, Sakarya, Turkey
}

"Corresponding author: Altintoprak Fatih, Department of General Surgery, Sakarya University Faculty of Medicine, Sakarya, Turkey. Tel: +905335483415; Email: fatihaltintoprak@yahoo.com

Citation: Fatih A, Yusuf A, Yener UM (2017) Diagnosis and Evaluation of Corrosive Oesophageal Injuries. J Surg: JSUR-162. DOI: 10.29011/JSUR-162.000062

Received Date: 06 August, 2017; Accepted Date: 19 September, 2017; Published Date: 26 September, 2017

\begin{abstract}
Corrosive oesophageal injuries are a common health problem worldwide, particularly in developing countries. The most important causes include the daily use of corrosive substances for cleaning purposes, easy access, lack of descriptive labels on storage containers and, most importantly, inadequate education. Prevention has a huge role in reducing the incidence of corrosive esophageal injuries.

The severity of injury depends on the type and concentration of the corrosive substance and the duration of mucosal exposure. Following their intake orally, corrosive substances can cause severe injuries to the oesopha-gus (e.g. esophagitis and oesophagus perforation after acute exposure, stricture and cancer development after chronic exposure). Therefore, the proper management of corrosive injuries is crucial. Immediate treatment is usually conservative, but the patients with clinical or radiological evidence of perforation require immediate laparotomy, usually followed by esophagectomy and other surgical options. Cause of the rarity of this entity, there is no standard surgical treatment algorithms. Here, we summarise the management options for oesopha-geal injuries due to corrosive substances.
\end{abstract}

Keywords: Corrosive; Corrosive Injury; Oesophageal Injury

\section{Introduction}

Liquid and crystal forms of corrosive substances are commonly used in industrial and house cleaning. Acci-dental or suicidal intake of these substances is a major health problem worldwide $[1,2]$. Following the intake of corrosive substances orally, rapidly progressing and severe injuries can develop in the upper gastrointestinal system after acute exposure; stricture and cancer can develop after chronic exposure. Endoscopic examination facilitates determination of the extent and severity of injury during the early period. Steroid and antibiotic treatment, use of oesophageal stents, timing of dilatation methods, and the type of and indications for surgery [1,3-5] are still debated.

\section{General Information}

Corrosive injuries occur most commonly during childhood, with the greatest risk from 1-3 years of age. Gold-man [6] reported that patients $<5$ years and $>21$ years of age are at the highest risk for corrosive injuries; the number of cases of corrosive substance intake is $\sim 5,000$ per annum in the United States of America alone [7]. Liquid cleaning reagents, which are stored in the home in bottles/boxes of various sizes, are among the com-mon causative agents of injuries during childhood. In addition, small batteries, which are often stored in loca-tions that can be accessed by children, are an important cause of injury. Corrosive substance intake during childhood usually occurs by accident and in small amounts. Therefore, the outcome is generally better. In adults, accidental intake is also prevalent; however, intake with suicidal intent is more common. In such cases, the resulting injury is usually more severe, since the substance is consumed deliberately and in excessive amounts. The mortality rate in cases of corrosive substance intake is $10-20 \%$; this increases to $78 \%$ in cases of suicidal intent $[3,6,8]$.

The physical features of the substance can determine the localisation of the lesions. For instance, solid-granular substances can cause burns in the hypopharynx and upper oesophagus, while liquid substances can cause burns in the entire oesophagus and in the stomach. Acidic substances cause less severe injuries, as they lead to coagulation necrosis; conversely, alkaline substances cause 
Citation: Fatih A, Yusuf A, Yener UM (2017) Diagnosis and Evaluation of Corrosive Oesophageal Injuries. J Surg: JSUR-162.

more severe problems, as they lead to liquefaction necrosis $[5,8]$.

\section{Physiopathology}

The histological changes in the oesophagus following corrosive substance intake were classified for the first time in 1951 [9]. According to this classification, the degree of injury can be summarised as follows: submuco-sal edema or congestion, vascular thrombosis and submucosal inflammation, peeling of the superficial layer, necrosis in the muscular layer, fibrosis in deep layers and late re-epithelisation. Superficial mucosal burns generally heal without any complications. Burns in the muscular layer heal with fibrosis; however, a circular injury is likely to result in stricture.

Within the first 2 weeks following the burn, inflammation occurs, necrotic tissues dissociate and granulation and new collagen tissues develop. Between the third and fourth weeks, collagen contraction begins, which can result in cicatrisation. Transmural necrosis in the oesophagus can result in perforation, which is associated with high rates of mortality and morbidity [10]. Regardless of the nature of the corrosive substance (alkaline or acid-ic), the degree of injury is related to the concentration, quantity and physical features of the substance, existing physical structure of the exposed tissue and the duration of exposure. Alkaline agents cause greater oesopha-geal injury compared with acidic agents due to rapid loss of contact with acidic agents (which cause sudden pain), longer exposure to alkaline agents (which are odourless and tasteless) and the alkaline $\mathrm{pH}$ of the oesoph-agus and pharynx. In addition, alkaline agents cause liquefaction necrosis, while acidic agents cause coagula-tion necrosis [11]. Following coagulation necrosis, coagulum and scar tissue formation in the exposed area prevent the injury from progressing into deeper layers. In the case of liquefaction necrosis, however, protein and collagen breakdown, lipid saponification, dehydration and thrombosis occur, which have a greater effect on deeper tissues.

The $\mathrm{pH}$ value of alkaline agents is also an important determinant of the mechanism of injury. Experimental studies have shown that agents of $\mathrm{pH} 12.5$ and 13 can cause oesophageal strictures; agents of $\mathrm{pH} 14$ cause the most severe injuries [10]. The differences between alkaline and acidic corrosive injuries are summarized in (Ta-ble 1).

\begin{tabular}{|c|c|}
\hline ALKALINE AGENTS & ACIDIC AGENTS \\
\hline Common in Western populations & Common in Eastern populations \\
\hline $\mathrm{pH}>7$ & $\mathrm{pH}<7$ \\
\hline Tasteless, odourless & Strong odour \\
\hline Liquefaction necrosis & Coagulation necrosis \\
\hline Deeper injury & More superficial injury \\
\hline High rate of oesophageal injury & High rate of stomach injury \\
\hline
\end{tabular}

\begin{tabular}{|l|l} 
Absence of protective scar & Presence of protective scar
\end{tabular}

Table 1: Differences between injuries caused by alkaline and acidic agents.

The anatomical features of the oesophagus also determine the localisation and degree of injury. The most se-vere injuries occur in narrow anatomical structures, where the duration of exposure is highest. Since the shape of small batteries attracts children, corrosive injuries caused by battery ingestion are more common during childhood. Battery-related injuries occur as a result of the combination of caustic damage (exposure of the alkaline battery content) and thermal damage (due to electrical activity) [12]. As batteries are solid, their likeli-hood of becoming lodged in narrow anatomical structures is higher. In addition, the high concentration of acids in batteries leads to localised effects. Therefore, these substances represent a serious danger to children.

\section{Grading}

For corrosive esophagitis, a clinical classification similar to that of skin burns is used. This classification is de-tailed as follows:

First-degree injury: Involves only the mucosa. Mucosal edema and hyperaemic appearance are pre-sent. Heals without complications.

Second-degree injury: Involves the submucosa and the muscular layer. Ulceration, necrosis and gen-eral mucosal shedding are seen. Ulcerations heal with development of granulation tissue during the early stages and with fibroblastic reaction and collagen synthesis during the late stages. Due to the de-velopment of scar tissue, stricture development can occur between 8 weeks and 8 months.

Third-degree injury: Involves transmural injury with possible perforation, which can also affect ex-tra-oesophageal tissues.

The correct identification of the degree of injury is crucial for treatment planning. However, it should be noted that this classification is generally a subjective evaluation, and a third-degree injury can easily be classified as a second-degree injury.

\section{Diagnosis}

As for every disease, the first step in the diagnosis of corrosive injuries involves obtaining a detailed anamnesis. During questioning, it is critical to learn the time of intake and the content(s) of the substance involved. The optimal means of ascertaining the content is to have access to the container or bottle. In the case of children, it is not possible to obtain an anamnesis. Because the parents are likely to be worried, any information they pro-vide regarding the contents of the substance may not be reliable. Similarly, attempting to determine the con-tents verbally in a case of substance intake with suicidal intention will not yield reliable results. The 
Citation: Fatih A, Yusuf A, Yener UM (2017) Diagnosis and Evaluation of Corrosive Oesophageal Injuries. J Surg: JSUR-162.

clinical find-ings of corrosive injuries vary and include increased saliva secretion due to irritation, difficulty in swallowing due to edema, ulceration of the soft palate and pharynx, vocal coarsening or aphonia, dyspnoea or stridor, odinophagy, retrosternal pain, epigastric pain and haematemesis. These findings can be present at the time of admission or can appear over the following hours or even days. However, it should not be assumed that pa-tients with a burn in the oral mucosa have no additional injuries or that patients without any complaints have no injuries. Early findings are not present in $10 \%$ of patients with very severe injuries, and additional injuries are not detected in $70 \%$ of patients with mucosal burns [13]. The symptoms and findings related to corrosive inju-ries are summarised in (Table 2).

\begin{tabular}{|c|c|}
\hline Mild and moderate & Severe \\
\hline Odinophagy & Stridor \\
\hline Chest pain & Agitation \\
\hline Back ache & Cyanosis \\
\hline Abdominal ache & Hypoxia \\
\hline Vomiting & Coughing \\
\hline Haematemesis & Fever \\
\hline Oral mucosal ulceration & Leucocytosis \\
\hline Drooling & Tachycardia \\
\hline Tongue edema & Shock \\
\hline Vocal coarsening & \\
\hline
\end{tabular}

Table 2: Symptoms and findings in corrosive injuries.

Among the various radiological methods, Postero-Anterior (PA) lung graphy and direct abdominal graphy can facilitate early diagnosis of severe injuries. These methods enable detection of aspiration-related pulmonary changes, pneumomediastinum in cases of oesophagus perforation, subdiaphragmatic free gas and subcutane-ous emphysema during the early stages. It is also possible to detect perforations by water-soluble contrast to-mography examinations, which are of considerable utility in cases of chronic complications, such as stricture development. Barium examinations should not be performed during the early stages. These methods are useful when evaluating stricture formation after chronic exposure, or for the distal oesophagus/stomach, which can-not be examined endoscopically after acute exposure [14-16].

Endoscopic examination provides the most important findings for diagnosis. The endoscopic classification of corrosive injuries is summarised in (Table 3 ).

\begin{tabular}{|c|}
\hline Grade 0: Normal \\
\hline Grade I: Mucosal edema and hyperaemia \\
\hline Grade 2a: Superficial ulceration, erosion, exudate, mucosal fragility, \\
haemorrhage, white membranes \\
\hline Grade 2b: Grade 2a + mucosal deep clefts, peripheral ulcers \\
\hline
\end{tabular}

Grade 3a: Scattered areas with multiple ulcerations, necrotic areas with grey/brown/black colouration

Grade 3b: Widespread necrosis

Table 3: Endoscopic classification of corrosive oesophageal injuries.

Endoscopic examination should be performed by an experienced physician, since i) the oesophageal wall might be fragile due to injury, and ii) iatrogenic perforation is a possibility. The consensus on timing for endoscopic examination is in favour of early endoscopy. Generally, early endoscopy refers to the first 48 h. However, some authors advocate early endoscopic examination during the initial $36 \mathrm{~h}$, whereas others claim that endoscopic examinations within the first $96 \mathrm{~h}$ are free of procedure-related complications $[15,17]$. Other important tech-nical points are i) performing endoscopic examination under general anesthesia, ii) postponing the procedure for 7 days to avoid airway complications in cases of patients with severe oropharyngeal burns at the first endo-scopic examination, iii) maintaining minimal air insufflation and endoscope movement and iv) terminating the procedure following identification of the first burn area, before moving to distal locations [18]. According to a retrospective study of 273 patients [19], grade-3b injuries are the most common type (30\%) of injury, and stric-ture development occurs most frequently in this group of patients $(53.6 \%)$. Therefore, early endoscopy (within the first 24 h) is crucial for treatment planning and predicting morbidity and mortality. The advantages of early endoscopy include the ability to evaluate mucosal injury under direct view, which has a direct effect on treat-ment planning, and the ability to identify those who should be treated as inpatients. Early endoscopy also has limitations, including failure to detect the area of injury, deeper injury in cases of mucosal necrosis and distal injuries when the injury is located in the proximal oesophagus.

\section{Treatment}

Because the degree of injury cannot be determined at the initial evaluation, the most extreme scenario should be considered, and life-support treatment should be applied, similar to trauma patients. Airway patency should be assessed and vascular access established to ensure fluid resuscitation. In cases of severe injury, the possibil-ity of laryngeal edema or airway obstruction due to edema in later stages should be considered, and the need for intubation and even tracheostomy should be kept in mind. If intubation is necessary, possible necrosis in the proximal airway should be considered, and the procedure should be conducted under direct visualisation. Oral feeding should be avoided, analgesia should be maintained, and water or milk should not be consumed as antidotes [16]. These steps aim to stabilise the patient's general condition. Once the haemodynamic parameters are stabilised, patients should undergo lung and abdominal ultrasonography, and endoscopic examination should be performed within the first $24 \mathrm{~h}$. Following endoscopic examination, patients with first-degree injury will not 
require additional treatment and can be discharged once oral feeding is tolerated. Three weeks later, a barium examination should be performed to evaluate stricture development.6 More aggressive treatment proto-cols are required for patients with severe injuries, given the high risks of early- and late-stage complications, while emergency surgical intervention is necessary for patients with perforation.

The consensus concerning feeding is to start oral feeding in patients with normal swallowing function, following stabilisation of the haemodynamic parameters. Total parenteral feeding or nasogastric gastrostomy is neces-sary for patients with insufficient swallowing function. Endoscopy is essential for placement of nasogastric catheters. Due to the risk of perforation, a nasogastric catheter should not be placed blindly. Diverse opinions exist concerning the use of corticosteroids and antibiotics. Experimental studies have shown that steroid use during the early period decreases the rate of oesophageal stricture development [20,21]. It has been suggested that steroid use decreases stricture development [22]; however, other studies claim that steroid use is ineffective $[23,24]$. Currently, the general principles concerning the use of steroids for corrosive esophagitis treatment are as follows: steroid treatment is not necessary for first-degree injuries; steroids are not useful in cases of perfora-tion (third-degree injuries) or transmural necrosis and are potentially dangerous; if steroids are to be used, they should be used at high doses during the early stages and in combination with antibiotic treatment [10]. Use of antibiotics is recommend if i) infection findings are present, ii) a microorganism is identified or iii) steroid treat-ment is applied [18].

In addition, various studies on animals have reported that $\mathrm{N}$-acetylcysteine, penicillamine, mitomycin and cer-tain antineoplastic agents decrease stricture development by inhibiting protein synthesis and reducing collagen cross-linking. However, no clinical study has been carried out to date [8, 22,25]. Surgical treatment options can be classified as emergency surgical interventions and late reconstructive procedures. Emergency surgical inter-ventions are generally performed due to perforation, bleeding and mediastinitis; late reconstructive procedures, on the other hand, are performed due to recurrent dilatations and oesophagus strictures, which do not respond to steroid treatment or endoscopic stent applications [26-28]. Management of corrosive esophageal injuries involves urgent resuscitation with correction of fluid and electrolyte and acid-base abnormalities, administra-tion of broad spectrum antibiotics and immediate surgical exploration. The aim of surgery is remove all the non-viable tissue in once and do a thorough peritoneal and mediastinal drainage. A significantly higher mortali-ty has been reported in thoracoabdominal approach was used for esophageal resection [29]. Usually the injury is limited to the esophagus and stomach. All injured organs must be resected, if possible, during the first opera-tion for example pancreas, spleen and small intestine.
Emergency surgical interventions are esophagectomy, with distal and proximal stoma, esophagogastrectomy, feeding jejunostomy, and other resections. During esophagectomy, there is two options; transhiatal or trans-thorasic approach. The surgeons may prefer the transhiatal approach. If the patient's situation is stabile, the surgeons may perform reconstruction operations [30] has been reported in transthorasic approach was signifi-cantly higher mortality. Late surgical interventions are reconstruction operations such as gastric pull-up, colon transposition. Free jejunal interposition loops have also been described in the reconstructive surgery [29]. Re-construction is probably advisable at the end of the evolving scarring process, usually after 6 months [31]. Co-lonic transposition changes the gastrointestinal anatomy more than gastric pull-up and involves more than an anastomosis because it comes with increased morbidity and mortality [32]. Gastric damage commonly occurs in the antrum or corpus of the stomach. The useful diagnostic tools are eosophagogastroduodenal contrast studies and upper gastrointestinal endoscopy which show the extent and severity of injury body. The surgical options are total/ subtotal gastrectomy, antrectomy, gastrojeunostomy, pyloroplasty. the surgeons may choose the operation type for patient's affected site of stomach [33]. Treatment is generally insufficient in cases of widespread necrosis or perforation; thus, the clinical condition can rapidly lead to mediastinitis and sepsis, eventually resulting in mortality. In such cases, surgical options include esophagogastrectomy and late reconstruction or cervical esophagectomy and feeding jejunostomy. Treatment options for late-stage complications include intraluminal stents, endoscopic dilatation and late oesophageal reconstruction methods.

\section{Complications}

Complications following corrosive substance intake include pneumonia (chemical or aspiration), atelectasis, dysphagia, tracheobronchial fistule, gastrointestinal system bleeding, aortoentericgastrocholic fistules, perfora-tion, stricture and the development of malignancy. Malignancy development (squamous cell carcinoma) is a late-stage complication of severe corrosive injuries. The average rate of carcinoma development following cor-rosive strictures is $2.3-6.2 \%$, and the frequency of corrosive substance intake in all patients with oesophageal cancer is 1-4\% [34]. Corrosive substance intake increases the risk of carcinoma development 1000-fold compared with that in the normal population. Following corrosive substance intake, carcinoma development can take $\sim 40$ years. These carcinomas occur most commonly in the mid-oesophagus, which is consistent with the localisation of strictures. Concerning carcinoma development, controlled endoscopic examinations should be started 15-20 years after corrosive substance intake, and these examinations should be repeated at 1-3-year intervals [35]. The majority $(60-70 \%)$ of oesophageal strictures are of peptic origin and are localised in the squamocolumnar joint. Strictures are the most frequent chronic complication of corrosive esophagitis. Stricture 
Citation: Fatih A, Yusuf A, Yener UM (2017) Diagnosis and Evaluation of Corrosive Oesophageal Injuries. J Surg: JSUR-162.

development is a result of the recovery process after oesophageal injury. As expected, the likelihood of stricture development is directly proportional to the severity of injury. Stricture development is expected to occur in $15-30 \%$ of patients with a second-degree injury and in up to $90 \%$ of patients with a third-degree injury [36]. Stricture development results in the inability to perform normal swallowing functions and in malnutrition. Generally, a lumen diameter $>10 \mathrm{~mm}$ is sufficient to continue normal life; stenosis, which can prevent the forward movement of the endo-scopic guide or cause complete obstruction, can be seen in cases of severe injury. Various methods for mainte-nance of a normal lumen have been described. These include intraluminal stent placement in cases of deep partial or perforation-free transmural burns, dilatations with balloons or bougies, intralesional steroid applica-tions and by-pass procedures with or without resection.

Intraluminal stent applications were first described in experimental studies in the 1970s, and these stents have since been used in children and adults. Stents can be placed endoscopically or with the aid of gastrostomy. In addition, this process can be used in combination with antibiotic and steroid treatments, although successful treatment without steroid use has also been reported [37]. Various bougies and balloons are used for dilatation. Dilatations are not performed during the early stages due to the high risk of perforation and are considered only after stricture development. The procedure is usually performed in an anterograde manner. In cases of multiple strictures/strictures involving the esophagogastric junction, the procedure can be performed in a retrograde manner. Only experienced operators should perform dilatation procedures, since perforation is a frequently reported complication [10]; the rate of perforation during balloon dilatation is $\sim 20-25 \%$ and can be slightly higher in cases of perforation due to alkaline substances [38] reported that the rate of perforation is $22 \%$ during balloon dilatation in patients with strictures due to alkaline substance intake. If perforation develops during dilatation, the necessary steps required depend on the degree of perforation, as well as the clinical condition of the patient. In cases of small perforations, parenteral feeding, acid suppression treatment and antibiotic treat-ment can be used, provided that haemodynamic stability is ensured. On the other hand, surgical treatment may be required in cases of large perforations and haemodynamic instability. A disadvantage of balloon dilatation is that a single dilatation procedure is not always sufficient; repeated dilatations may be needed. It has been reported that balloon dilatation in combination with intralesional steroid treatment increases the success of dila-tation and decreases the number of dilatation procedures required [24]. Surgical intervention is not needed if adequate swallowing function is ensured by dilatation; however, reconstruction is necessary when dilatation is not successful. The stomach and colon are the most common organs used for reconstruction. Previous studies have discussed the necessity of an esophagectomy prior to reconstruction. Some authors support esophagec-tomy, due to the risk of cancer development in the remaining parts of the oesophagus, while others argue that a fibrotic oesophagus is prone to complications, and esophagectomy is not necessary due to a higher risk of complications than cancer development.

In a previous study, 68 patients with diffuse/multiple costic oesophageal strictures who had undergone surgical reconstruction due to unsuccessful treatment following corticosteroid treatment, repeated dilatation procedures and endoscopic stent placements were evaluated. Colonic interposition was preferred for reconstruction in 63 patients $(92.6 \%)$, partial esophagectomy and esophagogastrotomy in $3(4.4 \%)$ and jejunal interposition in 2 patients $(3 \%)$. According to a questionnaire on swallowing functions, 65 patients $(95.7 \%)$ had good swallowing function after an average period of 22 months (6 months to 8 years). With respect to complications, nine pa-tients (13.2\%) had anastomosis leak. two patients $(2.9 \%)$ had infections, three patients $(4.4 \%)$ had anastomotic stenosis, one patient $(1.4 \%)$ had intestinal obstruction, one patient $(1.4 \%)$ had pneumothorax, and one patient (1.4\%) had aspiration pneumonia. Overall, complications were detected in 19 patients (27.9\%) [1]. Previous studies have reported that using the stomach instead of the oesophagus during reconstruction has several dis-advantages, including gastroesophageal reflux, ulcer development and anastomosis stenosis. Other disad-vantages reported include the possibility that the stomach is affected by corrosive injury, and that the stomach is of insufficient length compared with the oesophagus. Jejunal interposition, on the other hand, is rarely used since vascular feeding can be easily damaged and it is not resistant to acids. Using the colon instead of the oe-sophagus has several advantages, including better blood flow, sufficient length, resistance to acids, and a lower incidence of stenosis development. Therefore, the colon is the preferred alternative to the oesophagus $[1,26,29]$.

In conclusion, corrosive oesophageal injury is a common health problem worldwide. Symptoms and findings at admission may not be correlated with the severity of the injury; thus, each patient should be considered to have severe trauma, and treatment should be applied accordingly. Following haemodynamic stabilisation, early en-doscopic examination is the most important step in treatment planning and prediction of clinical progress. It should be noted that existing injuries may lead to life-threatening complications even after acute exposure, and long-term follow up is vital.

\section{References}

1. Han Y, Cheng QS, Li XF, Wang XP (2004) Surgical management of esophageal strictures after caustic burns: a 30 years of experience. World J Gastroenterol 10: 2846-2849.

2. Adedeji TO, Tobih JE, Olaosun AO, Sogebi OA (2013) Corrosive oesophageal injuries: a preventable menace. Pan Afr Med J 15: 11.

3. Anderson KD, Rouse TM, Randolph JG (1990) A Controlled Trial of Corticosteroids in Children with Corrosive Injury of the Esophagus. Engl J Med 323: 637-640. 
Citation: Fatih A, Yusuf A, Yener UM (2017) Diagnosis and Evaluation of Corrosive Oesophageal Injuries. J Surg: JSUR-162.

4. Wasserman RL and Ginsburg CM (1985) Caustic substance injuries. J Pediatr 107: 169-174.

5. Karaoğlu AÖ and Özütemiz Ö (1998) Akut korozif özo-fajit: 108 olgunun değerlendirilmesi. Turk J Gastroenterol 1: 55-60.

6. Goldman LP and Weigert J9M (1984) Corrosive substance ingestion: a reviewAm J Gastroenterol 79: 85-90.

7. Moore WR (1986) Caustic ingestion. Pathophysiology, diagnosis, and treatment Clin Pediatr 25:192-196.

8. Lupa M, Magne J, Guarisco JL, Amedee R (2009) Update on the diagnosis and treatment of caustic ingestionOchsner J 9: 54-59.

9. Bosher LH, Burford TH, Ackerman L (1951) The pathology of experimentally produced lye burns and strictures of the esophagus. J Thorac Surg 21: 483-489.

10. Spiegel JR and Sataloff RT (2004) Caustic injıries of the esophagus. In: Castell DO, Richter JE (eds.), The esophagus (4th edition). Lippincott Williams \& Wilkins 2004: 602-610.

11. Ashcraft KW and Padula RT (1974) The effect of dilute corrosives on the esophagus. Pediatrics 53: 226-232.

12. Yasui $T$ (1986) Hazardous effect due to of alkaline button battery ingestion: an experimental study. Ann Emerg Med 15: 901-906.

13. Haller JA Jr, Andrews HG, White JJ, Tamer MA, Cleveland WW (1971) Pathophysiology and management of acute corrosive burns of the esophagus: results of treatment in 285 children. J Pediatr Surg 6: 578584 .

14. Tanen DA, Curry SC, Laney RF (1999) Renal failure and corrosive airway and gastrointestinal injury after ingestion of diluted diquat solution Ann Emerg Med 34: 542-545.

15. Zargar SA, Kochhar R, Mehta S, Mehta SK (1991) The role of fiberoptic endoscopy in the management of corrosive ingestion and modified endoscopic classification of burns. Gastrointest Endosc 37: 165-169.

16. Mamede RC and De Mello Filho FV (2002) Treatment of caustic ingestion: an analysis of 239 cases. Dis Esophagus 15: 210-213.

17. Hawkins DB, Demeter MJ, Barnett TE (1980) Caustic ingestion: controversies in management. A review of 214 cases. Laryngoscope 90: 98-109.

18. Keh SM, Onyekwelu N, McManus K, McGuigan J (2006) Corrosive injury to upper gastrointestinal tract: Still a major surgical dilemma. World J Gastroenterol 12: 5223-5228.

19. Cheng HT, Cheng CL, Lin CH, Tang JH, Chu YY, et al. (2008) Caustin ingestion in adults: The role of endoscopic classification in predicting outcome. BMC Gastroenterology 8: 31.

20. Bautista A, Tojo R, Varela R, Estevez E, Villanueva A, et al. (1996) Effects of prednisolone and dexamethasone on alkali burns of the esophagus in rabbit. J Pediatr Gastroenterol Nutr 22: 275-283.

21. Günel E, Çağlayan F, Çağlayan O, Canbilen A, Tosun M (2002) Effect of antioxidant therapy on collagen synthesis in corrosive esophageal burns. Pediatr Surg Int 18: 24-27.

22. Howell JM, Dalsey WC, Hartsell FW, Butzin CA (1992) Steroids for the treatment of corrosive esophageal injury: a statistical analysis of past studies. Am J Emerg Med 10: 421-425.
23. Ramasamy K and Gumaste VV (2003) Corrosive ingestion in adults. J Clin Gastroenterol 37: 119-124.

24. Kochhar R, Ray JD, Sriram PV, Kumar S, Singh K (1999) Intralesional steroids augment the effects of endoscopic dilation in corrosive esophageal strictures. Gastrointest Endosc 49: 509-513.

25. Oakes DD (1995) Reconsidering the diagnosis and treatment of patients following ingestion of liquid lye J Clin Gastroenterol 21: 85-86.

26. Rajabi MT, Maddah G, Bagheri R, Mehrabi M, Shabahang H, et al. (2015) Corrosive injury of the upper gastrointestinal tract: review of surgical management and outcome in 14 adult cases. Iran J Otorhinolaryngol 27: 15-21.

27. Estrera A, Taylor W, Mills LJ, Platt MR (1986) Corrosive burns of the esophagus and stomach: a recommendation for an aggressive surgical approach Ann Thorac Surg 41: 276-283.

28. Balumuka DD, Chalya PL, Mahalu W (2011) Oesophageal perforation: a diagnostic and therapeutic challenge in a resource limited setting. A report of three cases J Cardiothorac Surg 6: 116.

29. Solauri $J$ and Markkula $H$ (1989) Lye ingestion and carcinoma of the esophagus. Acta Chir Scand 155: 269-271.

30. Hirota WK, Zuckerman MJ, Adler DG, Davila RE, Egan J, et al. (2006) Standarts of Practice Committee, American Society of Gastrointestinal Endoscopy. ASGE guideline: the role of endoscopy in the surveillance of premalignant conditions of the upper GI tract.Gastrointest Endosc 63: $570-580$.

31. Gumaste VV and Dave PB (1992) Ingestion of corrosive substances by adults. Am J Gastroenterol 87: 1-5.

32. Berkovits RN, Bos CE, Wijburg FA, Holzki J (1996) Caustic injury of the oesophagus. Sixteen years' experience, and introduction of a new model oesophageal stent. J Laryngol Otol 110: 1041-1045.

33. Sunar H, Kocakuşak A, Akıncı M, Arıkan S, Şentürk O, et al. (2004) Korozif madde içilmesine bağlı özofagus striktürlerinde balon dilatasyon ve cerrahi tedavi deneyimlerimiz. Van Tıp Dergisi 11: 48-55.

34. Javed A, Pal S, Krishnan EK, Sahni P, Chattopadhyay TK (2012) Surgical management and outcomes of severe gastrointestinal injuries due to corrosive ingestion.World J Gastrointest Surg 4: 121-125.

35. Lai KH, Huang BS, Huang MH, Huang MS, Wu JK, et al. (1995) Emergency surgical intervention for severe corrosive injuries of the upper digestive tract. Zhonghua Yixue Zazhi (Taipei) 56: 40-46.

36. Contini S and Scarpignato C (2013) Caustic injury of the upper gastrointestinal tract: A comprehensive review. World J Gastroenterol 19: 3918-3930.

37. Harlak A, Yigit T, Coskun K, Ozer T, Mentes O, et al. (2013) Surgical treatment of caustic esophageal strictures in adults. International Journal of Surgery 11: 164-168.

38. Gupta V, Wig JD, Kochhar R, Sinha SK, Nagi B, et al. (2009) Surgical management of gastric cicatrisation resulting from corrosive ingestion. Int J Surg 7: 257-261. 